\title{
Shared experiences of mental health services in Verona and London
}

\author{
Verena Penwanger and Michael Phelan
}

Close links have developed between the Institute of Psychiatry at the University of Verona - a town in North-East Italy - and the Maudsley Hospital in South London. Reciprocal visits, exchanges and cooperation in clinical practice and research have led to interesting experiences and comparisons between the different cultural settings and mental health services. In 1993. one of us (MP) visited the South Verona Psychiatric Service for two weeks, and a year later VP spent six months attached to the South Camberwell Community Team and at PRiSM (Psychiatric Research in Service Measurement), a research team at the Institute of Psychiatry. This paper records our impressions and observations during these visits. The two services are not representative of all services in the respective countries but the visits did give us the opportunity to consider details not revealed by formal comparative research studies.

There are fundamental differences in the development of community psychiatry in the two countries. In Italy, a radical reform was initiated by psychiatrists (Basaglia, 1968) and established through 'Law 180' in 1978. This established structural changes in service organisation, as well as changes to the underlying 'philosophy' (Tansella \& Williams, 1987; Mosher \& Burti, 1989). The law stopped further admissions of patients with severe mental illness to public mental hospitals, and transferred the responsibility for psychiatric care to multidisciplinary community teams. These teams are fully responsible for all psychiatric patients within a defined geographic area (except those with drug problems and learning difficulties and only in part for those with alcohol and psychogeriatric problems) and are expected to co-ordinate all interventions for the patients. There is no access to special services, such as forensic or eating disorder units, outside the sector and the team must manage all the problems and find solutions using resources within the sector. The focus of psychiatric care is, therefore, not just on individual patients and the biological aspects of their illness, but also on their social context, family background, strengths of the patient and potential resources available within his or her environment. The relationship between patient or family and professional is the main therapeutic tool, which encourages creativity and unconventional solutions (Siani et al, 1990, Mosher \& Burti, 1989).

Compared with Italy, British community psychiatry has developed slowly, and until recently remained complementary to traditional hospital-based treatment. While psychiatric reform - at least in its theory - is widely supported among mental health staff in Italy, there appears to be more caution and ambivalence about changes in psychiatric services among mental health staff in Britain. There continues to be a distinction between out-patients, and those who are more chronically ill, non-compliant or difficult to engage and are referred to the community team, if out-patient treatment is insufficient. A more 'medical' model of psychiatric illness results in greater emphasis being given to drug treatment and less recognition of the therapeutic relationship between professional and patient. This is reflected by a different understanding of 'continuity of care'. In Italy one or more professionals will follow a patient through the different phases of his or her illness, regardless of the treatment setting, whereas in Britain continuity of care will 
usually mean sustained contact with a given team or facility, but not necessarily the same individual professionals.

\section{Service structure and organisation}

Italy is divided into local socio-sanitary units (ULSS, Unita' Locale Socio-Sanitaria with 100,000 to 200,000 inhabitants) which are responsible for the whole range of social, medical and sanitary needs of the population. Psychiatric services are a part of these units and are centrally administered by them. So, compared with Britain, where services are increasingly managing their own budgets, in Italy there is less autonomy and all decisions must be approved by a general administration-a time-consuming and inefficient process. The structure in Britain appears to allow for a more flexible, quicker response to users' needs.

In Italy there are fewer specialised agencies such as housing and welfare departments and work training centres and fewer facilities for patients (e.g. independent day centres, sheltered flats, hostels) than in Britain. There are also fewer in-patient beds. In Italy there are usually 15 beds per psychiatric service, situated in general hospitals, which are designated for acute short-term and compulsory admissions. In South Verona, 15 beds are available for 75.000 inhabitants, and they are rarely full. The core of the Italian psychiatric service is the community mental health centre, which provides a broad range of interventions: day care, crisis intervention, medication, informal support, social contacts, free meals and creative activities.

\section{Professionals}

There are major differences in the approach to training doctors. In Italy, to become a specialist in psychiatry trainees spend four years at a university department after an initial admission examination. Trainees are involved in regular clinical activities with normal working hours as well as out of hours rotas. Each year, they must pass several exams and at the end of the four years they must submit a thesis. In South-Verona rotation from the community team to the psychotherapy unit or the 'Servizio di Psicologia Medica', which includes responsibility for the sheltered flats and the mental health centre, is possible after two years. Unlike Britain, Italian doctors in training are not formally employed, but since 1991 have received a grant by the Ministry of Rome (approximately $\$ 8,600$ a year) and have to pay an annual fee (in 1994 approximately $£ 800$ ). As a result many of them cannot afford an independent life and need financial support from their families. If they get ill or pregnant, they have virtually no economic security. However, once employed in the public sector, pregnant women in Italy receive more protection than in Britain: maternity leave in Britain is eight weeks with full and ten weeks with half payment, while in Italy the obligatory maternity leave with full pay-goes from two months (in high-risk jobs like psychiatry three months) before the due date until three months after the delivery. After this, a further six months of facultative leave is possible (45 days with $100 \%$ and the rest with $30 \%$ of pay). This period is alternatively available for the father, while in the NHS paternity leave is currently restricted to six days' unpaid leave.

There are significant differences in the organisation of the multidisciplinary team between South Verona and Camberwell. In South Verona the key-worker is almost always a doctor - usually a psychiatrist in training - who, with continuing feedback from the team, decides and coordinates the treatment plan. He or she decides when to involve other professionals. The contact, especially with long-term patients is, therefore, more frequent and intense and less focused on assessment and prescription. In Britain, many of these tasks are carried out by nurses, reflecting the generally higher status of nurses and their more specific training, responsibility and autonomy. In Italy nurses usually have their job for life, with few chances of promotion. This contributes to the stability and continuity of the service. However, the stimulation resulting from research, teaching and responsibility in service planning and management - as observed in Camberwell - appears to increase staff motivation and enhances service development. Social workers in Italy are integrated members of the teams and have the direct responsibility for housing, benefits and managing patients' money but are not involved in compulsory admission. Occupational therapists and secretaries are rare and precious in Italy-resulting in a higher burden for medical staff. 


\section{Patient management}

Although the pattern of patients' symptoms, behaviour and communication is similar, there are marked differences in social background and the consequences of illness between the two areas. The population of South Verona is predominantly white, middle to lower-class, with a traditional Italian background, in which values such as family, social support and religion - sometimes superstition - have great importance. Most patients live with or are at least supported by their families, which, even if often characterised by conflict and tension, are one of the most important resources for psychiatric services. In the Camberwell area, problems of social deprivation are higher and severely ill patients are frequently homeless, with little or no social support. Secondary alcohol and drug abuse is common. The higher mobility makes long-term follow-up and continuity of care more difficult. Aggresstve and violent behaviour appears far more common in Camberwell. The number of compulsory admissions in South Verona is very low, approximately 10 to 12 per year, and the length of admission is shorter than in London (the mean duration of hospital admissions is about 18 days in South Verona and 39 days in South London).

There are also differences in physical treatments. Benzodiazepines are very carefully prescribed in Britain while in Italy they are available in almost every home. In Italy there are almost twice as many substances on the market and benzodiazepines which are not available in Britain, such as triazolam, are widely used. This difference raises two issues. First, the rate of benzodiazepine-dependence in the two countries; second, the implications and consequences of the increasing use of paracetamol and other analgesics for suicide attempts in Britain (Charlton et al, 1994) while in Italy benzodiazepines are still the main substances taken in overdose and the use of paracetamol is rare. Dosages of neuroleptics seem to be slightly higher in Britain than in Italy, although there are marked differences between services as well. The recommended maximum doses of some tricyclic antidepressants (amitriptyline, desipramine, nortriptyline) are between 50 and $100 \mathrm{mg}$ higher in Italy but this difference does not appear to affect clinical practice. ECT continues to be a standard treatment in Britain while it is now rarely used in South Verona and many other services in Italy.
Finally, there were striking differences in the co-operation between general practitioners and psychiatrists. In Britain psychiatrists are regularly working in GP surgeries, whereas in Italy the contacts with GPs are more informal, and co-operation in South Verona is concentrated on training GPs in order to encourage early referral to the specialist.

\section{Conclusions}

These are just some of the most evident differences between the two cultural settings and their psychiatric services. In addition, many subtle nuances, unwritten rules and differences in life-style and interpersonal communication were found.

We both enjoyed and benefited from the experience of visiting another service in a different cultural setting. We went home more appreciative of some aspects of our countries' services but also full of ideas about how things could be improved.

\section{Acknowledgements}

We would both like to thank the many people who made our visits possible, enjoyable and successful. Michael Phelan was supported by the Robert Malcolm Trust.

\section{References}

BASAgla, F. (1968) L'Istituzione Negata. Torino: Einaudi.

Charlton, J., Kelly, S., DunNel, K., Evans, B. \& Jenkins, R. (1994) Suicide deaths in England and Wales: trends in factors associated with suiclde deaths. In The Prevention of Suicide (eds. R. Jenkins, S. Griffiths, I. Wylie, K. Hawton, G. Morgan \& A. Tylee). London: HMSO.

MOSHER, L. R. \& BURT, L. (1989) Community Mental Health. Principles and Practice. New York: Norton \& Co.

SianI, R. SiCILIANI, O. \& BURT1. L. (1990) Strategia di Psicoterapia e Riabilitazione (Gli Psicotict e u Servizio Psichiatrico). Milano: Biblioteca di psichiatria e di psicologia clinica. Feltrinelli.

TANSElla, M. \& Willuams, P. (1987) The Italian experience and its implications. Psychological Medicine, 17, 283289.

Verena Perwanger, Istituto di Psichiatria, Universita' di Verona, Ospedale Policlinico, 37134, Verona, Italy; and "Michael Phelan, Assistant Director, PRiSM (Psychiatric Research in Service Measurement), Institute of Psychiatry, De Crespigny Park, London SE5 BAF

"Correspondence 